\title{
Notas sobre a experiência e o saber de experiência*
}

\author{
Jorge Larrosa Bondía
}

Universidade de Barcelona, Espanha

Tradução de João Wanderley Geraldi

Universidade Estadual de Campinas, Departamento de Lingüística

No combate entre você e o mundo, prefira o mundo.

Franz Kafka

Costuma-se pensar a educação do ponto de vista da relação entre a ciência e a técnica ou, às vezes, do ponto de vista da relação entre teoria e prática. Se o par ciência/técnica remete a uma perspectiva positiva e retificadora, o par teoria/prática remete sobretudo a uma perspectiva política e crítica. De fato, somente nesta última perspectiva tem sentido a palavra "reflexão" e expressões como "reflexão crítica", "reflexão sobre prática ou não prática", "reflexão emancipadora" etc. Se na primeira alternativa as pessoas que trabalham em educação são concebidas como sujeitos técnicos que aplicam com maior ou menor eficácia as

* Conferência proferida no I Seminário Internacional de Educação de Campinas, traduzida e publicada, em julho de 2001, por Leituras SME; Textos-subsídios ao trabalho pedagógico das unidades da Rede Municipal de Educação de Campinas/FUMEC. A Comissão Editorial agradece Corinta Grisolia Geraldi, responsável por Leituras $S M E$, a autorização para sua publicação na $R e$ vista Brasileira de Educação. diversas tecnologias pedagógicas produzidas pelos cientistas, pelos técnicos e pelos especialistas, na segunda alternativa estas mesmas pessoas aparecem como sujeitos críticos que, armados de distintas estratégias reflexivas, se comprometem, com maior ou menor êxito, com práticas educativas concebidas na maioria das vezes sob uma perspectiva política. Tudo isso é suficientemente conhecido, posto que nas últimas décadas o campo pedagógico tem estado separado entre os chamados técnicos e os chamados críticos, entre os partidários da educação como ciência aplicada e os partidários da educação como práxis política, e não vou retomar a discussão.

O que vou lhes propor aqui é que exploremos juntos outra possibilidade, digamos que mais existencial (sem ser existencialista) e mais estética (sem ser esteticista), a saber, pensar a educação a partir do par experiência/sentido. O que vou fazer em seguida é sugerir certo significado para estas duas palavras em distintos contextos, e depois vocês me dirão como isto lhes soa. O que vou fazer é, simplesmente, explorar algumas palavras e tratar de compartilhá-las.

E isto a partir da convicção de que as palavras 
produzem sentido, criam realidades e, às vezes, funcionam como potentes mecanismos de subjetivação. Eu creio no poder das palavras, na força das palavras, creio que fazemos coisas com as palavras e, também, que as palavras fazem coisas conosco. As palavras determinam nosso pensamento porque não pensamos com pensamentos, mas com palavras, não pensamos a partir de uma suposta genialidade ou inteligência, mas a partir de nossas palavras. E pensar não é somente "raciocinar" ou "calcular" ou "argumentar", como nos tem sido ensinado algumas vezes, mas é sobretudo dar sentido ao que somos e ao que nos acontece. E isto, o sentido ou o sem-sentido, é algo que tem a ver com as palavras. E, portanto, também tem a ver com as palavras o modo como nos colocamos diante de nós mesmos, diante dos outros e diante do mundo em que vivemos. E o modo como agimos em relação a tudo isso. Todo mundo sabe que Aristóteles definiu o homem como zôon lógon échon. A tradução desta expressão, porém, é muito mais "vivente dotado de palavra" do que "animal dotado de razão" ou "animal racional". Se há uma tradução que realmente trai, no pior sentido da palavra, é justamente essa de traduzir logos por ratio. E a transformação de zôon, vivente, em animal. O homem é um vivente com palavra. E isto não significa que o homem tenha a palavra ou a linguagem como uma coisa, ou uma faculdade, ou uma ferramenta, mas que o homem é palavra, que o homem é enquanto palavra, que todo humano tem a ver com a palavra, se dá em palavra, está tecido de palavras, que o modo de viver próprio desse vivente, que é o homem, se dá na palavra e como palavra. Por isso, atividades como considerar as palavras, criticar as palavras, eleger as palavras, cuidar das palavras, inventar palavras, jogar com as palavras, impor palavras, proibir palavras, transformar palavras etc. não são atividades ocas ou vazias, não são mero palavrório. Quando fazemos coisas com as palavras, do que se trata é de como damos sentido ao que somos e ao que nos acontece, de como correlacionamos as palavras e as coisas, de como nomeamos o que vemos ou o que sentimos e de como vemos ou sentimos o que nomeamos.

Nomear o que fazemos, em educação ou em qual- quer outro lugar, como técnica aplicada, como práxis reflexiva ou como experiência dotada de sentido, não é somente uma questão terminológica. As palavras com que nomeamos o que somos, o que fazemos, o que pensamos, o que percebemos ou o que sentimos são mais do que simplesmente palavras. E, por isso, as lutas pelas palavras, pelo significado e pelo controle das palavras, pela imposição de certas palavras e pelo silenciamento ou desativação de outras palavras são lutas em que se joga algo mais do que simplesmente palavras, algo mais que somente palavras.

1. Começarei com a palavra experiência. Poderíamos dizer, de início, que a experiência é, em espanhol, "o que nos passa". Em português se diria que a experiência é "o que nos acontece"; em francês a experiência seria "ce que nous arrive"; em italiano, "quello che nos succede" ou "quello che nos accade"; em inglês, "that what is happening to us"; em alemão, "was mir passiert".

A experiência é o que nos passa, o que nos acontece, o que nos toca. Não o que se passa, não o que acontece, ou o que toca. A cada dia se passam muitas coisas, porém, ao mesmo tempo, quase nada nos acontece. Dir-se-ia que tudo o que se passa está organizado para que nada nos aconteça. ${ }^{1}$ Walter Benjamin, em um texto célebre, já observava a pobreza de experiências que caracteriza o nosso mundo. Nunca se passaram tantas coisas, mas a experiência é cada vez mais rara.

Em primeiro lugar pelo excesso de informação. A informação não é experiência. E mais, a informação não deixa lugar para a experiência, ela é quase o contrário da experiência, quase uma antiexperiência. Por isso a ênfase contemporânea na informação, em estar informados, e toda a retórica destinada a constituirnos como sujeitos informantes e informados; a informação não faz outra coisa que cancelar nossas possi-

${ }^{1}$ Em espanhol, o autor faz um jogo de palavras impossível no português: "Se diria que todo lo que pasa está organizado para que nada nos pase", exceto se optássemos por uma tradução como "Dir-se-ia que tudo que se passa está organizado para que nada se nos passe" (Nota do tradutor). 
bilidades de experiência. $\mathrm{O}$ sujeito da informação sabe muitas coisas, passa seu tempo buscando informação, o que mais o preocupa é não ter bastante informação; cada vez sabe mais, cada vez está melhor informado, porém, com essa obsessão pela informação e pelo saber (mas saber não no sentido de "sabedoria", mas no sentido de "estar informado"), o que consegue é que nada lhe aconteça. A primeira coisa que gostaria de dizer sobre a experiência é que é necessário separá-la da informação. E o que gostaria de dizer sobre o saber de experiência é que é necessário separá-lo de saber coisas, tal como se sabe quando se tem informação sobre as coisas, quando se está informado. É a língua mesma que nos dá essa possibilidade. Depois de assistir a uma aula ou a uma conferência, depois de ter lido um livro ou uma informação, depois de ter feito uma viagem ou de ter visitado uma escola, podemos dizer que sabemos coisas que antes não sabíamos, que temos mais informação sobre alguma coisa; mas, ao mesmo tempo, podemos dizer também que nada nos aconteceu, que nada nos tocou, que com tudo o que aprendemos nada nos sucedeu ou nos aconteceu.

Além disso, seguramente todos já ouvimos que vivemos numa "sociedade de informação". E já nos demos conta de que esta estranha expressão funciona às vezes como sinônima de "sociedade do conhecimento" ou até mesmo de "sociedade de aprendizagem". Não deixa de ser curiosa a troca, a intercambialidade entre os termos "informação", "conhecimento" e "aprendizagem". Como se o conhecimento se desse sob a forma de informação, e como se aprender não fosse outra coisa que não adquirir e processar informação. E não deixa de ser interessante também que as velhas metáforas organicistas do social, que tantos jogos permitiram aos totalitarismos do século passado, estejam sendo substituídas por metáforas cognitivistas, seguramente também totalitárias, ainda que revestidas agora de um look liberal democrático. Independentemente de que seja urgente problematizar esse discurso que se está instalando sem crítica, a cada dia mais profundamente, e que pensa a sociedade como um mecanismo de processamento de informação, o que eu quero apontar aqui é que uma sociedade constituída sob o signo da informação é uma sociedade na qual a experiência é impossível.

Em segundo lugar, a experiência é cada vez mais rara por excesso de opinião. O sujeito moderno é um sujeito informado que, além disso, opina. É alguém que tem uma opinião supostamente pessoal e supostamente própria e, às vezes, supostamente crítica sobre tudo o que se passa, sobre tudo aquilo de que tem informação. Para nós, a opinião, como a informação, converteu-se em um imperativo. Em nossa arrogância, passamos a vida opinando sobre qualquer coisa sobre que nos sentimos informados. E se alguém não tem opinião, se não tem uma posição própria sobre o que se passa, se não tem um julgamento preparado sobre qualquer coisa que se lhe apresente, sente-se em falso, como se lhe faltasse algo essencial. E pensa que tem de ter uma opinião. Depois da informação, vem a opinião. No entanto, a obsessão pela opinião também anula nossas possibilidades de experiência, também faz com que nada nos aconteça.

Benjamin dizia que o periodismo é o grande dispositivo moderno para a destruição generalizada da experiência. ${ }^{2}$ O periodismo destrói a experiência, sobre isso não há dúvida, e o periodismo não é outra coisa que a aliança perversa entre informação e opinião. O periodismo é a fabricação da informação e a fabricação da opinião. E quando a informação e a opinião se sacralizam, quando ocupam todo o espaço do acontecer, então o sujeito individual não é outra coisa que o suporte informado da opinião individual, e o sujeito coletivo, esse que teria de fazer a história segundo os velhos marxistas, não é outra coisa que o suporte informado da opinião pública. Quer dizer, um sujeito fabricado e manipulado pelos aparatos da informação e da opinião, um sujeito incapaz de experiência. E o fato de o periodismo destruir a experiência é algo mais profundo e mais geral do que aquilo que derivaria do efeito dos meios de comunicação de massas sobre a conformação de nossas consciências.

O par informação/opinião é muito geral e permeia

\footnotetext{
${ }^{2}$ Benjamin problematiza o periodismo em várias de suas
} obras; ver, por exemplo, Benjamim, 1991, p. 111 e ss. 
também, por exemplo, nossa idéia de aprendizagem, inclusive do que os pedagogos e psicopedagogos chamam de "aprendizagem significativa". Desde pequenos até a universidade, ao largo de toda nossa travessia pelos aparatos educacionais, estamos submetidos a um dispositivo que funciona da seguinte maneira: primeiro é preciso informar-se e, depois, há de opinar, há que dar uma opinião obviamente própria, crítica e pessoal sobre o que quer que seja. A opinião seria como a dimensão "significativa" da assim chamada "aprendizagem significativa". A informação seria o objetivo, a opinião seria o subjetivo, ela seria nossa reação subjetiva ao objetivo. Além disso, como reação subjetiva, é uma reação que se tornou para nós automática, quase reflexa: informados sobre qualquer coisa, nós opinamos. Esse "opinar" se reduz, na maioria das ocasiões, em estar a favor ou contra. Com isso, nos convertemos em sujeitos competentes para responder como Deus manda as perguntas dos professores que, cada vez mais, se assemelham a comprovações de informações e a pesquisas de opinião. Diga-me o que você sabe, diga-me com que informação conta e exponha, em continuação, a sua opinião: esse o dispositivo periodístico do saber e da aprendizagem, o dispositivo que torna impossível a experiência.

Em terceiro lugar, a experiência é cada vez mais rara, por falta de tempo. Tudo o que se passa passa demasiadamente depressa, cada vez mais depressa. E com isso se reduz o estímulo fugaz e instantâneo, imediatamente substituído por outro estímulo ou por outra excitação igualmente fugaz e efêmera. $\mathrm{O}$ acontecimento nos é dado na forma de choque, do estímulo, da sensação pura, na forma da vivência instantânea, pontual e fragmentada. A velocidade com que nos são dados os acontecimentos e a obsessão pela novidade, pelo novo, que caracteriza o mundo moderno, impedem a conexão significativa entre acontecimentos. Impedem também a memória, já que cada acontecimento é imediatamente substituído por outro que igualmente nos excita por um momento, mas sem deixar qualquer vestígio. O sujeito moderno não só está informado e opina, mas também é um consumidor voraz e insaciável de notícias, de novidades, um curioso impenitente, eternamente insatisfeito. Quer estar permanentemente excitado e já se tornou incapaz de silêncio. Ao sujeito do estímulo, da vivência pontual, tudo o atravessa, tudo o excita, tudo o agita, tudo o choca, mas nada lhe acontece. Por isso, a velocidade e o que ela provoca, a falta de silêncio e de memória, são também inimigas mortais da experiência.

Nessa lógica de destruição generalizada da experiência, estou cada vez mais convencido de que os aparatos educacionais também funcionam cada vez mais no sentido de tornar impossível que alguma coisa nos aconteça. Não somente, como já disse, pelo funcionamento perverso e generalizado do par informação/ opinão, mas também pela velocidade. Cada vez estamos mais tempo na escola (e a universidade e os cursos de formação do professorado são parte da escola), mas cada vez temos menos tempo. Esse sujeito da formação permanente e acelerada, da constante atualização, da reciclagem sem fim, é um sujeito que usa o tempo como um valor ou como uma mercadoria, um sujeito que não pode perder tempo, que tem sempre de aproveitar o tempo, que não pode protelar qualquer coisa, que tem de seguir o passo veloz do que se passa, que não pode ficar para trás, por isso mesmo, por essa obsessão por seguir o curso acelerado do tempo, este sujeito já não tem tempo. E na escola o currículo se organiza em pacotes cada vez mais numerosos e cada vez mais curtos. Com isso, também em educação estamos sempre acelerados e nada nos acontece.

Em quarto lugar, a experiência é cada vez mais rara por excesso de trabalho. Esse ponto me parece importante porque às vezes se confunde experiência com trabalho. Existe um clichê segundo o qual nos livros e nos centros de ensino se aprende a teoria, o saber que vem dos livros e das palavras, e no trabalho se adquire a experiência, o saber que vem do fazer ou da prática, como se diz atualmente. Quando se redige o currículo, distingue-se formação acadêmica e experiência de trabalho. Tenho ouvido falar de certa tendência aparentemente progressista no campo educacional que, depois de criticar o modo como nossa sociedade privilegia as aprendizagens acadêmicas, pretende implantar e homologar formas de contagem de 
créditos para a experiência e para o saber de experiência adquirido no trabalho. Por isso estou muito interessado em distinguir entre experiência e trabalho e, além disso, em criticar qualquer contagem de créditos para a experiência, qualquer conversão da experiência em créditos, em mercadoria, em valor de troca. Minha tese não é somente porque a experiência não tem nada a ver com o trabalho, mas, ainda mais fortemente, que o trabalho, essa modalidade de relação com as pessoas, com as palavras e com as coisas que chamamos trabalho, é também inimiga mortal da experiência.

O sujeito moderno, além de ser um sujeito informado que opina, além de estar permanentemente agitado e em movimento, é um ser que trabalha, quer dizer, que pretende conformar o mundo, tanto o mundo "natural" quanto o mundo "social" e "humano", tanto a "natureza externa" quanto a "natureza interna", segundo seu saber, seu poder e sua vontade. $\mathrm{O}$ trabalho é esta atividade que deriva desta pretensão. $\mathrm{O}$ sujeito moderno é animado por portentosa mescla de otimismo, de progressismo e de agressividade: crê que pode fazer tudo o que se propõe (e se hoje não pode, algum dia poderá) e para isso não duvida em destruir tudo o que percebe como um obstáculo à sua onipotência. $\mathrm{O}$ sujeito moderno se relaciona com o acontecimento do ponto de vista da ação. Tudo é pretexto para sua atividade. Sempre está a se perguntar sobre o que pode fazer. Sempre está desejando fazer algo, produzir algo, regular algo. Independentemente de este desejo estar motivado por uma boa vontade ou uma má vontade, o sujeito moderno está atravessado por um afã de mudar as coisas. E nisso coincidem os engenheiros, os políticos, os industrialistas, os médicos, os arquitetos, os sindicalistas, os jornalistas, os cientistas, os pedagogos e todos aqueles que põem no fazer coisas a sua existência. Nós somos sujeitos ultra-informados, transbordantes de opiniões e superestimulados, mas também sujeitos cheios de vontade e hiperativos. E por isso, porque sempre estamos querendo o que não é, porque estamos sempre em atividade, porque estamos sempre mobilizados, não podemos parar. E, por não podermos parar, nada nos acontece.

A experiência, a possibilidade de que algo nos aconteça ou nos toque, requer um gesto de interrupção, um gesto que é quase impossível nos tempos que correm: requer parar para pensar, parar para olhar, parar para escutar, pensar mais devagar, olhar mais devagar, e escutar mais devagar; parar para sentir, sentir mais devagar, demorar-se nos detalhes, suspender a opinião, suspender o juízo, suspender a vontade, suspender o automatismo da ação, cultivar a atenção e a delicadeza, abrir os olhos e os ouvidos, falar sobre o que nos acontece, aprender a lentidão, escutar aos outros, cultivar a arte do encontro, calar muito, ter paciência e dar-se tempo e espaço.

2. Até aqui, a experiência e a destruição da experiência. Vamos agora ao sujeito da experiência. Esse sujeito que não é o sujeito da informação, da opinião, do trabalho, que não é o sujeito do saber, do julgar, do fazer, do poder, do querer. Se escutamos em espanhol, nessa língua em que a experiência é "o que nos passa", o sujeito da experiência seria algo como um território de passagem, algo como uma superfície sensível que aquilo que acontece afeta de algum modo, produz alguns afetos, inscreve algumas marcas, deixa alguns vestígios, alguns efeitos. Se escutamos em francês, em que a experiência é "ce que nous arrive", o sujeito da experiência é um ponto de chegada, um lugar a que chegam as coisas, como um lugar que recebe o que chega e que, ao receber, lhe dá lugar. E em português, em italiano e em inglês, em que a experiência soa como "aquilo que nos acontece, nos sucede", ou "happen to us", o sujeito da experiência é sobretudo um espaço onde têm lugar os acontecimentos.

Em qualquer caso, seja como território de passagem, seja como lugar de chegada ou como espaço do acontecer, o sujeito da experiência se define não por sua atividade, mas por sua passividade, por sua receptividade, por sua disponibilidade, por sua abertura. Trata-se, porém, de uma passividade anterior à oposição entre ativo e passivo, de uma passividade feita de paixão, de padecimento, de paciência, de atenção, como uma receptividade primeira, como uma disponibilidade fundamental, como uma abertura essencial.

O sujeito da experiência é um sujeito "ex-pos- 
to". Do ponto de vista da experiência, o importante não é nem a posição (nossa maneira de pormos), nem a "o-posição" (nossa maneira de opormos), nem a "imposição" (nossa maneira de impormos), nem a "proposição" (nossa maneira de propormos), mas a "exposição", nossa maneira de "ex-pormos", com tudo o que isso tem de vulnerabilidade e de risco. Por isso é incapaz de experiência aquele que se põe, ou se opõe, ou se impõe, ou se propõe, mas não se "ex-põe". É incapaz de experiência aquele a quem nada lhe passa, a quem nada lhe acontece, a quem nada lhe sucede, a quem nada o toca, nada lhe chega, nada o afeta, a quem nada o ameaça, a quem nada ocorre.

3. Vamos agora ao que nos ensina a própria palavra experiência. A palavra experiência vem do latim experiri, provar (experimentar). A experiência é em primeiro lugar um encontro ou uma relação com algo que se experimenta, que se prova. O radical é periri, que se encontra também em periculum, perigo. A raiz indo-européia é per, com a qual se relaciona antes de tudo a idéia de travessia, e secundariamente a idéia de prova. Em grego há numerosos derivados dessa raiz que marcam a travessia, o percorrido, a passagem: peirô, atravessar; pera, mais além; peraô, passar através, perainô, ir até o fim; peras, limite. Em nossas línguas há uma bela palavra que tem esse per grego de travessia: a palavra peiratês, pirata. O sujeito da experiência tem algo desse ser fascinante que se expõe atravessando um espaço indeterminado e perigoso, pondo-se nele à prova e buscando nele sua oportunidade, sua ocasião. A palavra experiência tem o ex de exterior, de estrangeiro, de exílio, de estranho ${ }^{4}$ e também o ex de existência. A experiência é a passagem da existência, a passagem de um ser que não tem essência ou razão ou fundamento, mas que simplesmente " $e x$-iste" de uma forma sempre singular, finita, imanente, contingente. Em alemão, experiência é Erfahrung, que contém ofahren de viajar. E do antigo alto-alemão fara também deriva Gefahr, perigo, e

\footnotetext{
${ }^{3}$ Em espanhol, escreve-se extranjero. (Nota do tradutor)

${ }^{4}$ Em espanhol, extraño. (Nota do tradutor)
}

gefährden, pôr em perigo. Tanto nas línguas germânicas como nas latinas, a palavra experiência contém inseparavelmente a dimensão de travessia e perigo.

4. Em Heidegger (1987) encontramos uma definição de experiência em que soam muito bem essa exposição, essa receptividade, essa abertura, assim como essas duas dimensões de travessia e perigo que acabamos de destacar:

\section{[...] fazer uma experiência com algo significa que algo}

nos acontece, nos alcança; que se apodera de nós, que nos tomba e nos transforma. Quando falamos em "fazer" uma experiência, isso não significa precisamente que nós a façamos acontecer, "fazer" significa aqui: sofrer, padecer, tomar o que nos alcança receptivamente, aceitar, à medida que nos submetemos a algo. Fazer uma experiência quer dizer, portanto, deixar-nos abordar em nós próprios pelo que nos interpela, entrando e submetendo-nos a isso. Podemos ser assim transformados por tais experiências, de um dia para o outro ou no transcurso do tempo. (p. 143)

O sujeito da experiência, se repassarmos pelos verbos que Heidegger usa neste parágrafo, é um sujeito alcançado, tombado, derrubado. Não um sujeito que permanece sempre em pé, ereto, erguido e seguro de si mesmo; não um sujeito que alcança aquilo que se propõe ou que se apodera daquilo que quer; não um sujeito definido por seus sucessos ou por seus poderes, mas um sujeito que perde seus poderes precisamente porque aquilo de que faz experiência dele se apodera. Em contrapartida, o sujeito da experiência é também um sujeito sofredor, padecente, receptivo, aceitante, interpelado, submetido. Seu contrário, o sujeito incapaz de experiência, seria um sujeito firme, forte, impávido, inatingível, erguido, anestesiado, apático, autodeterminado, definido por seu saber, por seu poder e por sua vontade.

Nas duas últimas linhas do parágrafo, "Podemos ser assim transformados por tais experiências, de um dia para o outro ou no transcurso do tempo", pode lerse outro componente fundamental da experiência: sua capacidade de formação ou de transformação. É ex- 
periência aquilo que "nos passa", ou que nos toca, ou que nos acontece, e ao nos passar nos forma e nos transforma. Somente o sujeito da experiência está, portanto, aberto à sua própria transformação.

5. Se a experiência é o que nos acontece, e se o sujeito da experiência é um território de passagem, então a experiência é uma paixão. Não se pode captar a experiência a partir de uma lógica da ação, a partir de uma reflexão do sujeito sobre si mesmo enquanto sujeito agente, a partir de uma teoria das condições de possibilidade da ação, mas a partir de uma lógica da paixão, uma reflexão do sujeito sobre si mesmo enquanto sujeito passional. E a palavra paixão pode referir-se a várias coisas.

Primeiro, a um sofrimento ou um padecimento. No padecer não se é ativo, porém, tampouco se é simplesmente passivo. O sujeito passional não é agente, mas paciente, mas há na paixão um assumir os padecimentos, como um viver, ou experimentar, ou suportar, ou aceitar, ou assumir o padecer que não tem nada que ver com a mera passividade, como se o sujeito passional fizesse algo ao assumir sua paixão. Às vezes, inclusive, algo público, ou político, ou social, como um testemunho público de algo, ou uma prova pública de algo, ou um martírio público em nome de algo, ainda que esse "público" se dê na mais estrita solidão, no mais completo anonimato.

"Paixão" pode referir-se também a certa heteronomia, ou a certa responsabilidade em relação com o outro que, no entanto, não é incompatível com a liberdade ou a autonomia. Ainda que se trate, naturalmente, de outra liberdade e de outra autonomia diferente daquela do sujeito que se determina por si mesmo. A paixão funda sobretudo uma liberdade dependente, determinada, vinculada, obrigada, inclusa, fundada não nela mesma mas numa aceitação primeira de algo que está fora de mim, de algo que não sou eu e que por isso, justamente, é capaz de me apaixonar.

E "paixão" pode referir-se, por fim, a uma experiência do amor, o amor-paixão ocidental, cortesão, cavalheiresco, cristão, pensado como posse e feito de um desejo que permanece desejo e que quer permane- cer desejo, pura tensão insatisfeita, pura orientação para um objeto sempre inatingível. Na paixão, o sujeito apaixonado não possui o objeto amado, mas é possuído por ele. Por isso, o sujeito apaixonado não está em si próprio, na posse de si mesmo, no autodomínio, mas está fora de si, dominado pelo outro, cativado pelo alheio, alienado, alucinado.

Na paixão se dá uma tensão entre liberdade e escravidão, no sentido de que o que quer o sujeito é, precisamente, permanecer cativo, viver seu cativeiro, sua dependência daquele por quem está apaixonado. Ocorre também uma tensão entre prazer e dor, entre felicidade e sofrimento, no sentido de que o sujeito apaixonado encontra sua felicidade ou ao menos o cumprimento de seu destino no padecimento que sua paixão lhe proporciona. O que o sujeito ama é precisamente sua própria paixão. Mas ainda: o sujeito apaixonado não é outra coisa e não quer ser outra coisa que não a paixão. Daí, talvez, a tensão que a paixão extrema suporta entre vida e morte. A paixão tem uma relação intrínseca com a morte, ela se desenvolve no horizonte da morte, mas de uma morte que é querida e desejada como verdadeira vida, como a única coisa que vale a pena viver, e às vezes como condição de possibilidade de todo renascimento.

6. Até aqui vimos algumas explorações sobre o que poderia ser a experiência e o sujeito da experiência. Algo que vimos sob o ponto de vista da travessia e do perigo, da abertura e da exposição, da receptividade e da transformação, e da paixão. Vamos agora ao saber da experiência. Definir o sujeito da experiência como sujeito passional não significa pensá-lo como incapaz de conhecimento, de compromisso ou ação. A experiência funda também uma ordem epistemológica e uma ordem ética. O sujeito passional tem também sua própria força, e essa força se expressa produtivamente em forma de saber e em forma de práxis. $\mathrm{O}$ que ocorre é que se trata de um saber distinto do saber científico e do saber da informação, e de uma práxis distinta daquela da técnica e do trabalho.

O saber de experiência se dá na relação entre o conhecimento e a vida humana. De fato, a experiên- 
cia é uma espécie de mediação entre ambos. É importante, porém, ter presente que, do ponto de vista da experiência, nem "conhecimento" nem "vida" significam o que significam habitualmente.

Atualmente, o conhecimento é essencialmente a ciência e a tecnologia, algo essencialmente infinito, que somente pode crescer; algo universal e objetivo, de alguma forma impessoal; algo que está aí, fora de nós, como algo de que podemos nos apropriar e que podemos utilizar; e algo que tem que ver fundamentalmente com o útil no seu sentido mais estreitamente pragmático, num sentido estritamente instrumental. $\mathrm{O}$ conhecimento é basicamente mercadoria e, estritamente, dinheiro; tão neutro e intercambiável, tão sujeito à rentabilidade e à circulação acelerada como o dinheiro. Recordem-se as teorias do capital humano ou essas retóricas contemporâneas sobre a sociedade do conhecimento, a sociedade da aprendizagem, ou a sociedade da informação.

Em contrapartida, a "vida" se reduz à sua dimensão biológica, à satisfação das necessidades (geralmente induzidas, sempre incrementadas pela lógica do consumo), à sobrevivência dos indivíduos e da sociedade. Pense-se no que significa para nós "qualidade de vida" ou "nível de vida": nada mais que a posse de uma série de cacarecos para uso e desfrute.

Nestas condições, é claro que a mediação entre o conhecimento e a vida não é outra coisa que a apropriação utilitária, a utilidade que se nos apresenta como "conhecimento" para as necessidades que se nos dão como "vida" e que são completamente indistintas das necessidades do Capital e do Estado.

Para entender o que seja a experiência, é necessário remontar aos tempos anteriores à ciência moderna (com sua específica definição do conhecimento objetivo) e à sociedade capitalista (na qual se constituiu a definição moderna de vida como vida burguesa). Durante séculos, o saber humano havia sido entendido como um páthei máthos, como uma aprendizagem no e pelo padecer, no e por aquilo que nos acontece. Este é o saber da experiência: o que se adquire no modo como alguém vai respondendo ao que vai lhe acontecendo ao longo da vida e no modo como vamos dando sentido ao acontecer do que nos acontece. No saber da experiência não se trata da verdade do que são as coisas, mas do sentido ou do sem-sentido do que nos acontece. E esse saber da experiência tem algumas características essenciais que o opõem, ponto por ponto, ao que entendemos como conhecimento.

Se a experiência é o que nos acontece e se o saber da experiência tem a ver com a elaboração do sentido ou do sem-sentido do que nos acontece, trata-se de um saber finito, ligado à existência de um indivíduo ou de uma comunidade humana particular; ou, de um modo ainda mais explícito, trata-se de um saber que revela ao homem concreto e singular, entendido individual ou coletivamente, o sentido ou o sem-sentido de sua própria existência, de sua própria finitude. Por isso, o saber da experiência é um saber particular, subjetivo, relativo, contingente, pessoal. Se a experiência não é o que acontece, mas o que nos acontece, duas pessoas, ainda que enfrentem o mesmo acontecimento, não fazem a mesma experiência. $\mathrm{O}$ acontecimento é comum, mas a experiência é para cada qual sua, singular e de alguma maneira impossível de ser repetida. O saber da experiência é um saber que não pode separar-se do indivíduo concreto em quem encarna. Não está, como o conhecimento científico, fora de nós, mas somente tem sentido no modo como configura uma personalidade, um caráter, uma sensibilidade ou, em definitivo, uma forma humana singular de estar no mundo, que é por sua vez uma ética (um modo de conduzir-se) e uma estética (um estilo). Por isso, também o saber da experiência não pode beneficiar-se de qualquer alforria, quer dizer, ninguém pode aprender da experiência de outro, a menos que essa experiência seja de algum modo revivida e tornada própria.

A primeira nota sobre o saber da experiência sublinha, então, sua qualidade existencial, isto é, sua relação com a existência, com a vida singular e concreta de um existente singular e concreto. A experiência e o saber que dela deriva são o que nos permite apropriar-nos de nossa própria vida. Ter uma vida própria, pessoal, como dizia Rainer Maria Rilke, em Los Cuadernos de Malthe, é algo cada vez mais raro, quase tão raro quanto uma morte própria. Se chamamos 
existência a esta vida própria, contingente e finita, a essa vida que não está determinada por nenhuma essência nem por nenhum destino, a essa vida que não tem nenhuma razão nem nenhum fundamento fora dela mesma, a essa vida cujo sentido se vai construindo e destruindo no viver mesmo, podemos pensar que tudo o que faz impossível a experiência faz também impossível a existência.

7. A ciência moderna, a que se inicia em Bacon e alcança sua formulação mais elaborada em Descartes, desconfia da experiência. E trata de convertê-la em um elemento do método, isto é, do caminho seguro da ciência. A experiência já não é o meio desse saber que forma e transforma a vida dos homens em sua singularidade, mas o método da ciência objetiva, da ciência que se dá como tarefa a apropriação e o domínio do mundo. Aparece assim a idéia de uma ciência experimental. Mas aí a experiência converteu-se em experimento, isto é, em uma etapa no caminho seguro e previsível da ciência. A experiência já não é o que nos acontece e o modo como lhe atribuímos ou não um sentido, mas o modo como o mundo nos mostra sua cara legível, a série de regularidades a partir das quais podemos conhecer a verdade do que são as coisas e dominá-las. A partir daí o conhecimento já não é um páthei máthos, uma aprendizagem na prova e pela prova, com toda a incerteza que isso implica, mas um mathema, uma acumulação progressiva de verdades objetivas que, no entanto, permanecerão externas ao homem. Uma vez vencido e abandonado o saber da experiência e uma vez separado o conhecimento da existência humana, temos uma situação paradoxal. Uma enorme inflação de conhecimentos objetivos, uma enorme abundância de artefatos técnicos e uma enorme pobreza dessas formas de conhecimento que atuavam na vida humana, nela inserindo-se e transformando-a. A vida humana se fez pobre e necessitada, e o conhecimento moderno já não é o saber ativo que alimentava, iluminava e guiava a existência dos homens, mas algo que flutua no ar, estéril e desligado dessa vida em que já não pode encarnar-se.
A segunda nota sobre o saber da experiência pretende evitar a confusão de experiência com experimento ou, se se quiser, limpar a palavra experiência de suas contaminações empíricas e experimentais, de suas conotações metodológicas e metodologizantes. Se o experimento é genérico, a experiência é singular. Se a lógica do experimento produz acordo, consenso ou homogeneidade entre os sujeitos, a lógica da experiência produz diferença, heterogeneidade e pluralidade. Por isso, no compartir a experiência, trata-se mais de uma heterologia do que de uma homologia, ou melhor, trata-se mais de uma dialogia que funciona heterologicamente do que uma dialogia que funciona homologicamente. Se o experimento é repetível, a experiência é irrepetível, sempre há algo como a primeira vez. Se o experimento é preditível e previsível, a experiência tem sempre uma dimensão de incerteza que não pode ser reduzida. Além disso, posto que não se pode antecipar o resultado, a experiência não é o caminho até um objetivo previsto, até uma meta que se conhece de antemão, mas é uma abertura para o desconhecido, para o que não se pode antecipar nem "pré-ver" nem "pré-dizer".

JORGE LARROSA BONDÍA é doutor em pedagogia pela Universidade de Barcelona, Espanha, onde atualmente é professor titular de filosofia da educação. Publicou diversos artigos em periódicos brasileiros e tem dois livros traduzidos para o português: Imagens do outro (Vozes, 1998) e Pedagogia profana (Autêntica, 1999).

\section{Referências Bibliográficas}

HEIDEGGER, Martin, (1987). La esencia del habla. In

De camino al habla. Barcelona: Edicionaes del Serbal.

BENJAMIN, Walter, (1991). El narrador. In:__ Para uma critica de la violencia y otros ensaios. Madrid: Taurus, p. 111 e ss. (Ou, na edição brasileira: (1994). Magia e técnica, arte e política; ensaios sobre literatura e história da cultura. In: Obras escolhidas. $7^{\text {a }}$ ed., São Paulo: Brasiliense, vol. I). 


\section{Resumos/Abstracts}

Angela Xavier de Brito

Rei morto, rei posto? As lutas pela sucessão de Pierre Bourdieu no campo acadêmico francês

A morte de Bourdieu, que todos consideravam o maior sociólogo da língua francesa, deixou um grande vazio intelectual, difícil de ser preenchido.

Neste artigo, em um primeiro momento, a autora situa, para fins analíticos, os processos pelos quais a transmissão de sua herança tem sido feita, na esfera institucional, e as posições intelectuais, de seus principais seguidores, nela presentes. As oportunidades de aspirar a esta herança parecem estar divididas entre três candidatos:

Bernard Lahere, Jean-Claude

Kaufmann e Gisèle Sapiro, autores que estão em diferentes etapas de suas carreiras e os únicos a oferecer uma crítica respeitosa da teoria de Bourdieu e a propor sua extensão. Os primeiros dois autores partem do conceito de habitus e a última de campo. Conclui comentando como o desdobramento do pensamento de Bourdieu sobre a educação pode contribuir para o debate acadêmico brasileiro nessa área.

Palavras-chave: Pierre Bourdieu, sociologia da educação, campo educacional francês.

The King is dead, long live the King? The struggle to inherit Pierre Bourdieu's position in the French academic field

Bourdieu's death has left a great intellectual void in the French sociological community. This article intends, first of all, to state the struggles in the academic field that have followed this event. In order to show the processes by which the transmission of his inheritance has been carried out, we must distinguish the institutional assets, which could be bequeathed by Bourdieu himself to his followers, from the intellectual positions. The chances to aspire to this main inheritance seem to be divided between three candidates Bernard Lahire, Jean-Claude Kaufmann and Gisèle Sapiro authors who are at different stages of their careers. They seem to be the only ones to make a respectful critique of Bourdieu's theory and to propose its full extension. The first two authors begin from the concept of habitus, the last one from that of field. Last but not least, I intend to make some comments on how Bourdieu's theory can nourish the Brazilian academic debate in this domain.

Key-words: Pierre Bourdieu, educational sociology, french academic field.

Jorge Larrosa Bondía

Notas sobre a experiência e o saber de experiência

Propõe pensar-se a educação a partir do par experiência/sentido, contrapondo-se ao modo de pensar a educação como relação entre ciência e técnica, ou entre teoria e prática. Para tanto, explora o significado das palavras ex- periência e sentido. Quanto à primeira, critica o excesso de informação e a obrigatoriedade de ter opinião, posturas que estão na base da "aprendizagem significativa”. Critica também o excesso de trabalho, que não permite a experiência, e a própria relação trabalho/experiência. Quanto ao sentido, explora-o a partir do sujeito da experiência, definido não por sua atividade, mas pela abertura para ser transformado pela experiência - território de passagem, submetido a uma lógica da paixão. Afirma que o saber da experiência se dá na relação entre o conhecimento e a vida humana, singular e concreta.

Palavras-chave: experiência, saber de experiência, experiência/sentido.

\section{Notes on experience and the} knowledge of experience The text proposes to think education taking the pair experience/sense as its starting point, in opposition to that way of thinking education as a relation between science and technology or between theory and practice. To this end, it explores the meaning of the words experience and sense. With respect to the first, it criticises the excess of information and the obligation of having an opinion, postures which are at the base of "significant learning". It also criticises the excess of work which does not allow experience and the very relation work/experience. With relation to sense, this is explored on the basis of the subject of the experience, defined 
not by his/her activity but by the readiness to be transformed by experience - a human passageway, submitted to a logic of passion. It affirms that the knowledge of experience is acquired in the relationship between knowledge and human, singular concrete life.

Key-words: experience, knowledge of experience, experience/sense.

Lílian do Valle

Bases antropológicas da cidadania brasileira: sobre escola pública e cidadania na Primeira República Devido às fragilidades de sua implantação, não são poucos, no Brasil, a tratarem o regime republicano como uma simples continuação do período monárquico. Igualmente correntes, as críticas à tradição de constituição, no país, de um Estado forte e monopolizador, concedem cores de fatalidade à idéia da formação histórica de um cidadão inexoravelmente passivo, tipo antropológico definitivo, a marcar os rígidos limites à democratização da sociedade brasileira. Seria, assim, cabal a impossibilidade de a escola pública formar cidadãos - todos os argumentos em contrário consistindo apenas em novas reedições do velho mito da demiurgia educacional? Ao tentar reunir os elementos para análise das construções antropológicas que estão na base da experiência de cidadania brasileira, esse artigo coloca em perspectiva aquela que sem dúvida é a primeira e a mais central das exigências democráticas: a afirmação incondicional e incondicionada da igualdade política dos cidadãos. Palavras-chave: escola pública, Primeira República, cidadania.

\section{Anthropological bases of Brazilian} citizenship: on the public school and citizenship in the $1^{\text {st }}$ Republic Many critics treat the republican regi- me in Brazil as a simple continuation of the monarchic period due to the fragility of its implantation. Critics of the tradition of the creation of a strong monopoly state in the country are equally common-place and accord tones of fatality to the idea of the historical formation of an inexorably passive type of definitively anthropological citizen, setting rigid limits to the democratisation of Brazilian society. The impossibility of the public school forming citizens would thus be proven - all the arguments to the contrary consisting only of re-editions of the old myth of the educational demiurge? By attempting to unite elements capable of analysing these anthropological constructions which form the base of the experience of Brazilian citizenship, this article brings into perspective what is without a doubt the first and most central of democratic requirements: the unconditional and unconditionable affirmation of the political equality of citizens.

Key-words: Public school, $I^{s t}$ Republic, citizenship.

\section{Nora Krawczyk}

\section{A sustentabilidade da reforma} educacional em questão: a posição dos organismos internacionais $\mathrm{O}$ artigo discute temas e questões abordados pelas produções dos organismos internacionais a partir de 1998 como diferentes dimensões de sustentabilidade das reformas educacionais na América Latina, que oferecem interessantes indícios dos aspectos que receberam e continuarão recebendo investimentos - técnicos e financeiros desses organismos. Pelo menos três dimensões preocupam bastante os organismos internacionais: a dimensão política, a dimensão financeira e a dimensão técnica. Para sua análise, fo- ram examinadas as publicações do Banco Mundial, da CEPAL, do PREAL, do BID, do IIPE/UNESCO e da OREALC/UNESCO, desde 1998 até 2001.

Palavras-chave: reforma educacional, América Latina, organismos internacionais.

The sustainability of the educational reform in question: the position of the international organisations

This article discusses the themes and questions dealt with in the productions of international organisations from 1998 onwards with relation to different dimensions of the sustainability of the educational reforms in Latin America which offer interesting signs of those aspects which have and will continue to receive technical and financial investments from such organisations. At least three dimensions concern the international organisations: the political, the financial and the technical dimensions. This analysis is based on an examination of publications by the World Bank, CEPAL, PREAL, BID, IIPE/ UNESCO and OREALC/UNESCO, from 1998 to 2001.

Key-words: educational reform, Latin America, international organisations.

Victor Vincent Valla

Pobreza, emoção e saúde: uma discussão sobre pentecostalismo e saúde no Brasil

No campo de educação e saúde tem surgido um debate sobre a origem dos problemas de saúde, o qual propõe que a origem desses problemas está basicamente relacionado com as emoções mais do que com bactérias ou vírus. A teoria do apoio social sugere que, se as emoções são relacionadas ao surgimento das doenças, as soluções também estão relacionadas com 